\title{
Restoration of immunity in lymphopenic individuals with cancer by vaccination and adoptive T-cell transfer
}

\author{
Aaron P Rapoport ${ }^{1,4}$, Edward A Stadtmauer ${ }^{2,4}$, Nicole Aqui ${ }^{2,4}$, Ashraf Badros ${ }^{1}$, Julio Cotte ${ }^{2}$, Lisa Chrisley ${ }^{1}$, \\ Elizabeth Veloso ${ }^{2}$, Zhaohui Zheng ${ }^{2}$, Sandra Westphal ${ }^{1}$, Rebecca Mair ${ }^{2}$, Nina Chi ${ }^{2}$, Bashi Ratterree ${ }^{1}$, \\ Mary Francis Pochran ${ }^{1}$, Sabrina Natt ${ }^{1}$, Joanne Hinkle ${ }^{2}$, Cheryl Sickles ${ }^{2}$, Ambika Sohal ${ }^{2}$, Kathleen Ruehle ${ }^{1}$, \\ Christian Lynch ${ }^{3}$, Lei Zhang ${ }^{1}$, David L Porter ${ }^{2}$, Selina Luger ${ }^{2}$, Chuanfa Guo ${ }^{1}$, Hong-Bin Fang ${ }^{1}$, \\ William Blackwelder ${ }^{1}$, Kim Hankey ${ }^{1}$, Dean Mann ${ }^{1}$, Robert Edelman ${ }^{1}$, Carl Frasch ${ }^{3}$, Bruce L Levine ${ }^{2,4}$, \\ Alan Cross $^{1,4}$ \& Carl H June C $^{2,4}$
}

Immunodeficiency is a barrier to successful vaccination in individuals with cancer and chronic infection. We performed a randomized phase 1/2 study in lymphopenic individuals after high-dose chemotherapy and autologous hematopoietic stem cell transplantation for myeloma. Combination immunotherapy consisting of a single early post-transplant infusion of in vivo vaccineprimed and ex vivo costimulated autologous T cells followed by post-transplant booster immunizations improved the severe immunodeficiency associated with high-dose chemotherapy and led to the induction of clinically relevant immunity in adults within a month after transplantation. Immune assays showed accelerated restoration of CD4 T-cell numbers and function. Early T-cell infusions also resulted in significantly improved T-cell proliferation in response to antigens that were not contained in the vaccine, as assessed by responses to staphylococcal enterotoxin B and cytomegalovirus antigens $(P<0.05)$. In the setting of lymphopenia, combined vaccine therapy and adoptive T-cell transfer fosters the development of enhanced memory T-cell responses.

A prolonged and severe immune deficiency has prevented successful vaccination after high-dose chemotherapy and autologous stem cell transplantation ${ }^{1,2}$, leading to impaired immune responses against tumor and microbial antigens. Retrospective studies suggest that better clinical outcomes may be associated with more rapid lymphocyte recovery after transplant ${ }^{3}$. In addition, myeloma-reactive $\mathrm{T}$ cells have been detected at low frequencies in the marrow or blood of untreated individuals with myeloma ${ }^{4,5}$. Thus, strategies to augment the recovery and function of autologous $\mathrm{T}$ cells after transplant may be beneficial.

We hypothesized that combination immunotherapy consisting of the adoptive transfer of in vivo vaccine-primed $\mathrm{T}$ cells and posttransplant vaccination might provide a platform for post-transplant immunotherapy in the setting of chemotherapy-induced lymphopenia. We stimulated autologous $\mathrm{T}$ cells by coculture with immunomagnetic beads to which CD3-specific and CD28-specific monoclonal antibodies had been conjugated, based on studies showing that signals through CD3 and CD28 can prevent T-cell anergy ${ }^{6-10}$. For purposes of vaccination, we used the 7 -valent vaccine pneumococcal conjugate vaccine (PCV) because it invokes $\mathrm{T}$ cell-dependent antibody responses and is approved by the US Food and Drug Administration for use in children ${ }^{11}$. Using randomized design in which participants were assigned to receive T-cell infusions either on day 12 or day 100 after transplant, and either one pre- and two post-transplant PCV immunizations or two post-transplant immunizations only, we sought to determine: (i) whether adoptive transfer of costimulated autologous $\mathrm{T}$ cells could accelerate or improve recovery of acquired immunity, and (ii) whether vaccine-primed $\mathrm{T}$ cells administered in conjunction with immunizations could augment the development of pneumococcal immunity.

\section{RESULTS}

\section{Subjects and treatment}

We carried out a randomized phase $1 / 2$ trial in individuals with advanced myeloma to determine whether combination immunotherapy consisting of vaccination and adoptive T-cell transfer could correct the immunodeficiency and lymphopenia induced by high-dose chemotherapy (Fig. 1). We enrolled a total of 54 participants. We first carried out a single arm run-in phase to show the safety and feasibility of T-cell collection and expansion in this participant population and to work out logistical details. Twelve individuals participated in this phase. After the run-in phase, we enrolled 42 participants in a second phase of the protocol in which ex vivo-costimulated T-cell infusions were combined with immunizations using the 7-valent pneumococcal conjugate vaccine (PCV, Prevnar). We randomly assigned the 42

\footnotetext{
${ }^{1}$ University of Maryland Greenebaum Cancer Center and Center for Vaccine Development, 22 South Greene Street Baltimore, Maryland 21201, USA. ${ }^{2}$ Abramson Cancer Center, University of Pennsylvania, 421 Curie Boulevard Philadelphia, Pennsylvania 19104, USA. ${ }^{3}$ Food and Drug Administration, Center for Biologics Evolution and Research, 1401 Rockville Pike, Rockville, Maryland 20852, USA. ${ }^{4}$ These authors contributed equally to this work. Correspondence should be addressed to A.P.R.
} (arapoport@umm.edu) or C.H.J. (cjune@mail.med.upenn.edu).

Received 22 June; accepted 13 September; published online 16 October 2005; doi:10.1038/nm1310 
ARTICLES

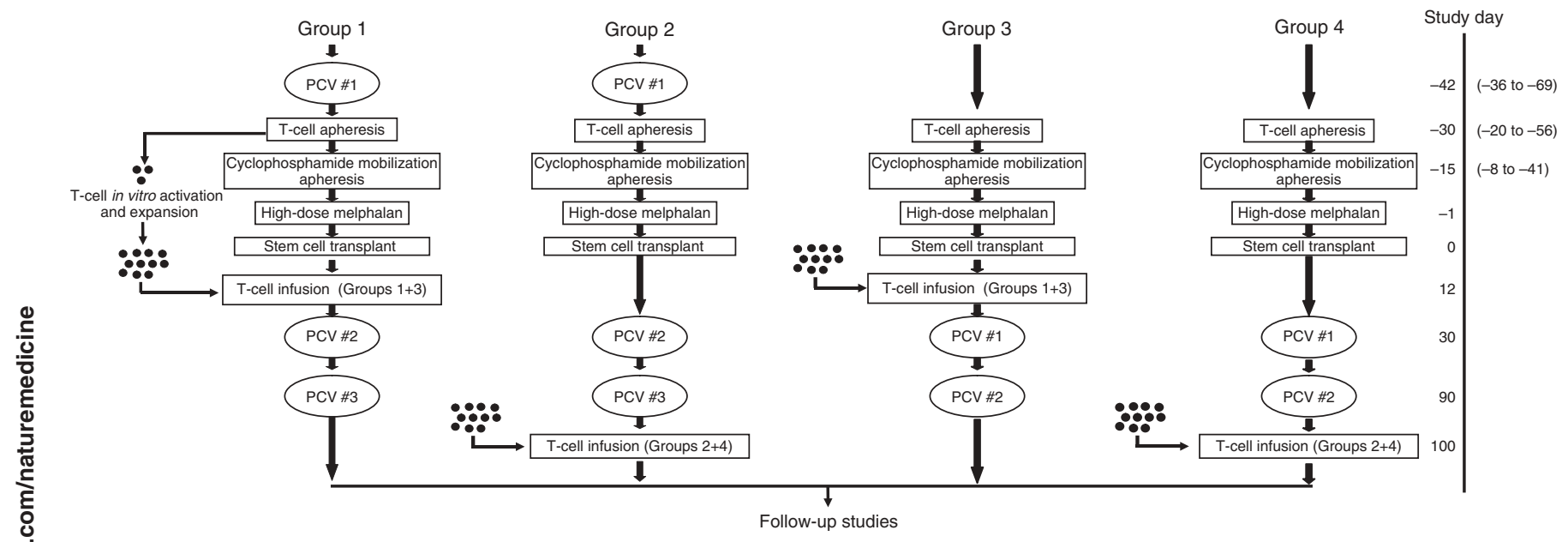

Figure 1 Protocol design. Study day 0 is designated as the day of hematopoietic stem cell transplantation. We performed two apheresis procedures to provide T cells for culture and $\mathrm{CD} 34^{+}$progenitor cells for transplantation.

participants to one of four different treatment groups using a random number generator (Fig. 1). Participants assigned to Group 1 received three PCV immunizations including: (i) about $10 \mathrm{~d}$ before the steadystate collection of mononuclear cells, (ii) at day 30 after transplant and (iii) at day 90 after transplant and also an infusion of costimulated T cells 'early', at day 12 after transplant. Participants assigned to

\section{Table 1 Subject characteristics}

\begin{tabular}{|c|c|c|c|}
\hline Characteristic & \multicolumn{2}{|r|}{ Value } & \\
\hline \multirow{3}{*}{ Total subjects enrolled } & \multirow{3}{*}{54} & $\longrightarrow$ & $\begin{array}{l}12 \text { nonrandomized } \\
\text { run-in phase }\end{array}$ \\
\hline & & & \\
\hline & & $\rightarrow$ & $\begin{array}{l}42 \text { randomized } \\
\text { subjects }\end{array}$ \\
\hline Median age & \multicolumn{2}{|c|}{56 years (range, $38-71$ ) } & \\
\hline \multicolumn{4}{|l|}{ Gender } \\
\hline Male & \multicolumn{2}{|c|}{$36(67 \%)$} & \\
\hline Female & \multicolumn{2}{|c|}{$18(33 \%)$} & \\
\hline \multicolumn{4}{|l|}{ Ethnicity } \\
\hline White & \multicolumn{2}{|c|}{$44(81 \%)$} & \\
\hline Black & \multicolumn{2}{|c|}{$10(19 \%)$} & \\
\hline \multicolumn{4}{|l|}{ Subtypes } \\
\hline $\lg G$ & \multicolumn{2}{|c|}{$31(58 \%)$} & \\
\hline $\lg A$ & \multicolumn{2}{|c|}{$12(22 \%)$} & \\
\hline Light chain only & \multicolumn{2}{|c|}{$11(20 \%)$} & \\
\hline $\begin{array}{l}\text { Median } \beta 2 \text {-microglobulin } \\
\text { (at diagnosis) }\end{array}$ & \multicolumn{2}{|c|}{$3.3(1.09-73.7)$} & \\
\hline Median number of prior regimens & \multicolumn{2}{|c|}{2 (range $1-5$ ) } & \\
\hline $\begin{array}{l}\text { Median percent plasmacytosis } \\
\text { (at diagnosis) }\end{array}$ & \multicolumn{2}{|c|}{$40 \%$ (range $2-100 \%$ ) } & \\
\hline \multicolumn{4}{|l|}{ Cytogenetics: } \\
\hline Normal & \multicolumn{2}{|c|}{$41(76 \%)$} & \\
\hline Unknown & \multicolumn{2}{|c|}{$5(9 \%)$} & \\
\hline Abnormal & \multicolumn{2}{|c|}{$8(15 \%)$} & \\
\hline del 13/13q: & \multicolumn{2}{|c|}{1} & \\
\hline ch. 11 abnormality: & \multicolumn{3}{|c|}{2 (+ other abnormalities) } \\
\hline Complex & \multicolumn{3}{|l|}{3} \\
\hline Other & \multicolumn{3}{|l|}{2} \\
\hline
\end{tabular}

Group 2 received three PCV immunizations as for the Group 1 participants, but received the T cells at study day 100 after transplant. Participants assigned to Group 3 received two PCV immunizations, one each at day 30 and day 90 after transplant only, along with an infusion of T cells at day 12 after transplant. Participants assigned to Group 4 received two PCV immunizations as for the Group 3 participants, but received $\mathrm{T}$ cells at $\sim$ day 100 after transplant. We randomly assigned 10 subjects each to Groups 1 and 2, and 11 subjects each to Groups 3 and 4 . Characteristics of the randomized groups were well balanced (Tables 1 and 2). There was no statistical difference, as determined by two-tailed $t$-test, among the groups in the total number of adoptively transferred $\mathrm{T}$ cells (Supplementary Fig. 1 online).

\section{T-cell recovery}

The randomized design of this trial (Fig. 1) afforded the opportunity to determine whether adoptive transfer of ex vivo costimulated polyclonal $\mathrm{T}$ cells could accelerate recovery of $\mathrm{CD}^{+}$or $\mathrm{CD}^{+} \mathrm{T}$-cell

Table 2 Subgroup characteristics

\begin{tabular}{|c|c|c|c|c|c|}
\hline \multirow[b]{2}{*}{ Characteristic } & \multicolumn{4}{|c|}{ Group } & \multirow[b]{2}{*}{$P$ value } \\
\hline & 1 & 2 & 3 & 4 & \\
\hline Number & 10 & 10 & 11 & 11 & \\
\hline Median age & 54.5 & 57.5 & 55 & 54 & 0.43 \\
\hline $\begin{array}{c}\text { Median marrow } \\
\text { plasmacytosis } \\
\text { (at diagnosis) }\end{array}$ & 40.5 & 40 & 40 & 65 & 0.74 \\
\hline $\begin{array}{l}\text { Median } \beta 2 \text {-microglobulin } \\
\text { (at diagnosis) }\end{array}$ & 3.9 & 3.1 & 3.5 & 3.6 & 0.88 \\
\hline Gender (male/female) & $6 / 4$ & $5 / 5$ & $9 / 2$ & $8 / 3$ & 0.45 \\
\hline $\begin{array}{l}\text { Abnormal cytogenetics } \\
\text { (number) }\end{array}$ & 1 & 2 & 2 & 2 & 0.99 \\
\hline $\begin{array}{l}\text { Number of prior regimens } \\
\text { (median, range) }\end{array}$ & $2(1-4)$ & $1(1-4)$ & $2(1-3)$ & $2(1-3)$ & 0.85 \\
\hline $\begin{array}{l}\text { Time from diagnosis } \\
\text { (median in months, range) }\end{array}$ & $\begin{array}{c}5.4 \\
(2.3-8.4)\end{array}$ & $\begin{array}{c}5.5 \\
(0.8-9.6)\end{array}$ & $\begin{array}{c}4.3 \\
(0.9-7.4)\end{array}$ & $\begin{array}{c}4.4 \\
(1.2-10.0)\end{array}$ & 0.63 \\
\hline
\end{tabular}



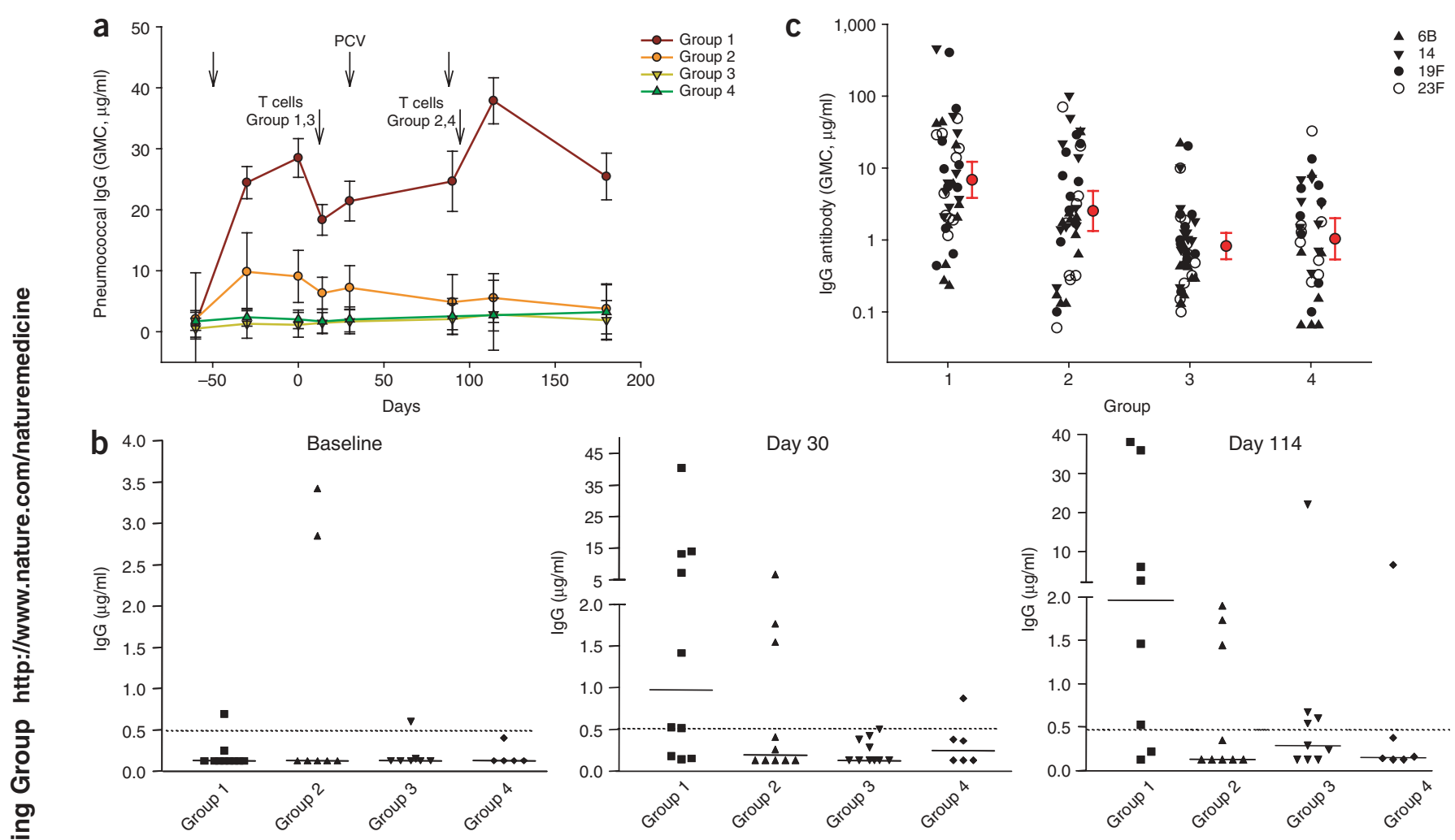

Figure 2 Time course and magnitude of total serum IgG antipneumococcal antibody responses. (a) Kinetics of response to serotypes $6 \mathrm{~B}, 14,19 \mathrm{~F}$ and $23 \mathrm{~F}$ in Groups 1-4. Individual ELISA assays specific for the indicated serotypes at each of the time points were performed, and the results were summed for each participant. The geometric mean antibody concentration is plotted (GMC $\pm 95 \%$ confidence interval $(\mathrm{CI}))$. Data represent $7-10$ participants per data point in Groups 1-3, and 5-7 participants per data point in Group 4. Group 1 is superior to Groups 2, 3 and 4 at days $42-180$ after transplant $(P<0.002)$. (b) Scattergrams of serum IgG levels to pneumococcal serotype 6B at baseline, and study day 30 and 114 for Groups 1-4, with a lower limit of detection of $0.13 \mu \mathrm{g} / \mathrm{ml}$. The GMC is indicated for each group; Group 1 is superior to Groups $2-4$ at day $30(P<0.03, P<0.01$ and $P=0.02$, respectively) and at day $114(P=0.02, P=0.07$ and $P=0.05$, respectively). Reference line indicates the threshold level that is potentially protective ( $>0.5 \mu \mathrm{g} / \mathrm{ml})$. (c) The peak serum antibody responses and the $\mathrm{GMC} \pm 95 \% \mathrm{Cl}$ (in red) of the peak responses during the first $180 \mathrm{~d}$ after transplant are plotted for serotypes $6 \mathrm{~B}$, $14,19 \mathrm{~F}$ and $23 \mathrm{~F}$ for Groups $1-4$. Group 1 is superior to Group $2(P=0.02)$ and Groups 3 and $4(P<0.001)$.

populations after chemotherapy-induced lymphopenia. We compared the geometric means of the $\mathrm{CD}^{+}$and $\mathrm{CD}^{+}$T-cell counts at transplant day +42 between these groups using the $t$-test with the Satterthwaite approximation method. The differences were significant ( $P=0.004$ for $\mathrm{CD}^{+}{ }^{+}$T-cell counts; $P=0.04$ for $\mathrm{CD}^{+}$T-cell counts; Supplementary Note online). These results indicate that an infusion of polyclonal costimulated $\mathrm{T}$ cells early after transplant can accelerate the recovery of $\mathrm{CD}^{+}$and $\mathrm{CD}^{+} \mathrm{T}$ cells after chemotherapy-induced lymphodepletion. The randomized $\mathrm{T}$-cell infusion groups did not differ with respect to the number of $\mathrm{CD}_{3} 4^{+}$progenitor cells or passenger lymphocytes that were infused at the time of autotransplantation.

\section{Studies of B-cell function}

We aimed to determine whether administration of a T cell-dependent conjugate vaccine for Streptococcus pneumoniae (PCV) combined with adoptively transferred $\mathrm{T}$ cells could enhance recovery of B- and T-cell function. We measured T-cell dependent antipneumococcal IgG antibody titers to serotypes $6 \mathrm{~B}, 14,19 \mathrm{~F}$ and $23 \mathrm{~F}$ for all study participants (Fig. 2a). The geometric mean responses of Groups 1 and 2 to the initial priming immunization were similar $(P=0.33)$, peaking between 12 and $28 \mu \mathrm{g} / \mathrm{ml}$ on day -30 . In contrast, the response of Group 1 was superior to Groups 2-4 at days 42 to 180 after transplantation $(P<0.002)$. In the period after transplant, the antipneumococcal antibody response rapidly waned nearly to baseline levels in Group 2, whereas Group 1 responded to post-transplant booster immunizations and had sustained antibody titers for the duration of the study. Groups 3 and 4 did not respond to posttransplant immunizations and had low or absent antibody levels throughout the study, confirming previous reports of severe posttransplant immunosuppression ${ }^{1,12,13}$.

There was considerable heterogeneity among subjects in the responses to the various capsular antigens contained in the vaccine (Fig. 2b). But the magnitude of the antipneumococcal responses to serotype $6 \mathrm{~B}$ in Group 1 subjects was superior to Groups 2-4, both early and late after transplantation $(P \leq 0.02)$. We selected serotype $6 \mathrm{~B}$ for analysis because it is considered to be poorly immunogenic ${ }^{14}$ and may thus be more representative of responses to tumor-antigens.

The robust magnitude and the kinetics of the antibody responses in some Group 1 subjects were notable. Although there is a lack of definitive serological correlates of protection for most of the pneumococcal serotypes included in polyvalent pneumococcal vaccines, in children antipneumococcal antibody levels of $>0.5 \mu \mathrm{g} / \mathrm{ml}$ have been shown to correlate with clinical protection from invasive disease ${ }^{15}$. As a reference level, this is a somewhat more conservative threshold than suggested in other studies ${ }^{16}$. At day 30, 6 of $10(60 \%)$ subjects in Group 1 were potentially protected against serotypes $6 \mathrm{~B}, 14,19 \mathrm{~F}$ and 
a

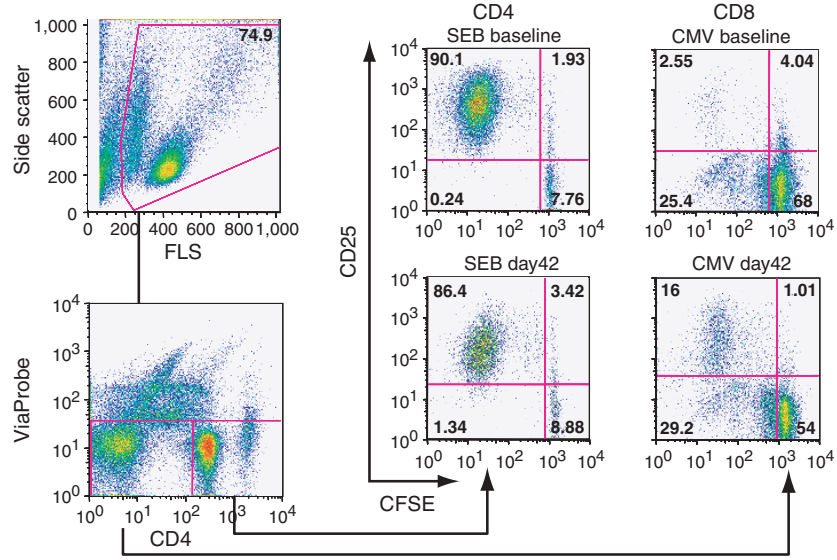

Figure 3 Longitudinal assessment of $\mathrm{CD}^{+}$and $\mathrm{CD} 8^{+} \mathrm{T}$-cell functional recovery after autologous transplantation and adoptive T-cell infusion. (a) Bivariate dot plots showing flow cytometric sequential analysis strategy using forward and side scatter, and ViaProbe and CD4 staining to identify the proliferative history of live $C D 25^{+} \mathrm{CFSE}^{\mathrm{dim}}$ cells. PBMC from a participant in Group 1 at baseline and day 42 were stimulated with staphylococcal enterotoxin B (SEB) or CMV, and analyzed on day 5.Values in the top left corner of the dot plots indicate the proportion of proliferative $\mathrm{CD}^{+}$or $\mathrm{CD}^{+}$ T cells. (b) Proliferative response of $\mathrm{CD}^{+}{ }^{+} \mathrm{T}$ cells after SEB stimulation $(0.1 \mu \mathrm{g} / \mathrm{ml})$ in participants given early (day 12) or late (day 100) T-cell infusions. Response (mean \pm s.e.m.) for early (Groups 1 and 3 ) and late (Groups 2 and 4) participants is shown. At days 42 and day 60 , the CD4 proliferative response of the early groups $(n=19)$ was superior to late participants $(n=16, P=0.004$ and $P=0.04$ for Groups 2 and 4 , respectively). (c) Proliferative response of CD4 ${ }^{+} \mathrm{T}$ cells to CRM-197 carrier protein stimulation is shown. Data for Groups 1 to 4 are indicated, as well as for Group 1 $(n=9)$ with the omission of a participant who had high baseline proliferation to CRM-197 (Gp1*,$n=8$ ). Both Group 1 and Group $1^{*}$ were superior to Groups 2-4 $(n=26)$ at day $42(P<0.01)$. (d) Longitudinal responses of $\mathrm{CD}^{+} \mathrm{T}$ cells to $\mathrm{CMV}$ stimulation. Responses of the CMV-seropositive participants from the early (Groups 1 and $3, n=11$ ) and late (Groups 2 and $4, n=10$ ) participants are shown. The CD8 proliferative response of the early groups was superior to late participants at day 42 and day 60 (mean \pm s.e.m., $P=0.02$ and $P=0.03$, respectively).
23F, whereas only 5 of 27 (18\%) subjects in Groups 2-4 were protected against all four serotypes ( $P=0.02$, chi-squared test). The cumulative peak antibody responses to serotypes $6 \mathrm{~B}, 14,19 \mathrm{~F}$ and $23 \mathrm{~F}$ were higher in Groups 1 and 2 than in Groups 3 and 4 (Fig. 2c). Given that the peak levels were $<1 \mu \mathrm{g} / \mathrm{ml}$ in many subjects in Groups 3 and 4 , these subjects were unlikely to be protected from invasive infection, indicating that the pre-transplant vaccine regimen schedule was superior to the post-transplantation-only schedule. Furthermore, when considering the subjects who received three vaccines (i.e., Groups 1 and 2), the peak titers were higher in Group 1 than in Group $2(P<0.02)$, consistent with the augmentation in mean titers by early $\mathrm{T}$-cell infusion (Fig. 3a). Finally, it is notable that the peak antibody levels were generally higher than has been reported in elderly and normal adult volunteers after PCV immunization ${ }^{17-21}$. Because the Group 1 treatment schedule differed from the Group 2 schedule only in the timing of the T-cell infusion, these results indicated that infusion of antigen-primed costimulated $\mathrm{T}$ cells early after transplant followed by booster immunizations leads to more robust and sustained $\mathrm{T}$ celldependent antibody responses.

\section{Studies of T-cell function}

The function of $\mathrm{T}$ cells, in particular $\mathrm{CD}^{+}$cells, is impaired for months to years after peripheral blood stem cell transplantation ${ }^{2}$. The accelerated numerical T-cell reconstitution combined with the augmented $\mathrm{T}$ cell-dependent IgG antibody responses to vaccination in
Group 1 subjects suggested that T-cell function was improved by early adoptive T-cell transfer after transplant. To address this issue, we isolated $\mathrm{T}$ cells from subjects at baseline and after vaccination and transplantation and stimulated them with a variety of antigens and mitogens to assess $\mathrm{CD}^{+}$and $\mathrm{CD}^{+}{ }^{+} \mathrm{T}$-cell function. We labeled the cells with a fluorescent dye and measured cell division by the halving of fluorescence with each generation (Fig. 3a). The T cell-proliferative responses were not concordant, with examples of maintained, improved or impaired responses observed in the same subject sample when pre-transplant and post-transplant $\mathrm{T}$ cell-proliferative responses were compared; for example, a subject from Group 1 maintained a robust $\mathrm{CD}^{+}{ }^{+} \mathrm{T}$ cell-proliferative response to staphylococcal enterotoxin B (SEB) on day 42 , whereas in the same subject the day $42 \mathrm{CD}^{+}$ $\mathrm{T}$ cell-proliferative response to cytomegalovirus (CMV) showed an increase (Fig. 3a).

We used the superantigen SEB to measure the general proliferative capacity of $\mathrm{CD}^{+} \mathrm{T}$ cells after transplantation, as the response to this mitogen should be independent of the relatively constricted T-cell receptor repertoire after transplantation ${ }^{22}$. All subjects had robust T-cell proliferation before transplant, as $85 \pm 3 \%$ of $\mathrm{CD}^{+} \mathrm{T}$ cells had diluted carboxyfluorescein succinimidyl ester (CFSE) content by day 5 of culture after SEB stimulation (Fig. 3b). But only the subjects given early T-cell infusions in Groups 1 and 3 had intact proliferative capacity on day 42 after transplant, whereas the subjects who had not yet received adoptively transferred T cells in Groups 2 and 4 
Table 3 T-cell infusion events

\begin{tabular}{lccccc}
\hline Toxicity & I & II & III & IV & Total \\
\hline Chills or rigors & $7(13 \%)$ & $21(40 \%)$ & 0 & 0 & $28(54 \%)$ \\
Fever & $9(17 \%)$ & $3(6 \%)$ & $2(4 \%)$ & 0 & $14(27 \%)$ \\
Nausea or vomiting & $7(13 \%)$ & $1(2 \%)$ & 0 & 0 & $8(15 \%)$ \\
Hypertension & $3(6 \%)$ & 0 & $1(2 \%)$ & 0 & $4(8 \%)$ \\
Hypotension & $2(4 \%)$ & 0 & 0 & 0 & $2(4 \%)$ \\
Pain or headache & $3(8 \%)$ & 0 & 0 & 0 & $3(8 \%)$ \\
Dyspnea or hypoxia & $1(2 \%)$ & $1(2 \%)$ & $1(2 \%)$ & 0 & $3(6 \%)$ \\
\hline
\end{tabular}

had impaired proliferation $(P<0.02)$. After the late T-cell infusion on study day 100, Groups 2 and 4 subjects experienced restoration of responsiveness to SEB.

We next assessed CD4 ${ }^{+}$T-cell responses to the CRM-197 protein. The pneumococcal vaccine is a 7 -valent vaccine that contains the capsular antigens for $S$. pneumoniae conjugated to a carrier protein, CRM-197 (ref. 23). At baseline, most subjects had low but detectable levels of $\mathrm{CD}^{+}{ }^{+}$T-cell proliferation to CRM-197, consistent with a central memory response (Fig. 3c). But one subject had high-level proliferation to both CRM-197 (64.5\%) and diphtheria toxoid (30.9\%, data not shown) at baseline, consistent with past infection with diphtheria or recent tetanus or diphtheria vaccine. Therefore, the data for Group 1 are presented with and without the inclusion of this subject. At $42 \mathrm{~d}$ after transplant, subjects in Group 1 had high levels of $\mathrm{CD}^{+}{ }^{+}$T-cell proliferation in response to CRM-197 stimulation, whereas all other groups were at baseline levels $(P<0.01)$. Thus, by comparing Groups 1 and 2, we concluded that a pre-transplant immunization with the protein conjugate vaccine alone was insufficient to confer restoration of antigen-specific $\mathrm{CD} 4^{+} \mathrm{T}$-cell function, whereas a pre-transplant immunization in combination with an early infusion of costimulated polyclonal $\mathrm{T}$ cells obtained after in vivo vaccine priming resulted in the generation of robust antigen-specific $\mathrm{CD}_{4}^{+}$ T-cell proliferation in the early period after transplant. The elevated level of proliferation was maintained for at least several months in the Group 1 subjects, consistent with the generation of memory T cells. All subjects received $\mathrm{T}$ cell-replete peripheral blood apheresis products for the stem cell graft on day 0 of the study; the grafts contained an average of $3 \times 10^{9}$ passenger $\mathrm{T}$ cells. Thus, the carryover of vaccine-primed resting $\mathrm{T}$ cells during the infusion of peripheral blood $\mathrm{T}$ cells collected during the stem cell mobilization apheresis was insufficient to prime this process, as we could not detect $\mathrm{CD} 4^{+} \mathrm{T}$-cell proliferation in Group 2 subjects above baseline until day 114 after transplant (i.e., 2 weeks after the late infusion of costimulated and primed T cells; Fig. 3c).

To determine whether the costimulated T-cell infusions had an effect on $\mathrm{CD}^{+} \mathrm{T}$-cell function, we evaluated the proliferative response to $\mathrm{CMV}$ in the subjects who were CMV seropositive. Beginning as early as day 42 after transplantation (i.e., $\sim 30 \mathrm{~d}$ after early T-cell infusion), there was an increased proliferative response of the $\mathrm{CD}^{+}$ $\mathrm{T}$ cells to CMV stimulation in subjects receiving early T-cell infusions that was superior to the response seen in the late T-cell infusion group (Fig. 3d, $P=0.02$ ). We did not detect $\mathrm{CMV}$ viremia or clinical infection in any of the subjects. Together, these results indicate that T-cell function in subjects improved in response to antigens in the vaccine, as assessed by CRM-197 and T cell-dependent antibody titers, after early T-cell infusion. But it is notable that the responses of T cells to antigens not contained in the vaccine improved as well, as shown by the responses to SEB and CMV stimulation. This indicates general improvement of T-cell proliferative capacity in the subjects, as it occurred independent of vaccination and was associated with early T-cell infusions. It is possible that homeostatic T-cell expansion contributed to the enhanced SEB and CMV responses, because the T-cell levels were higher in the early group (Supplementary Fig. 2 online).

\section{Clinical outcomes}

The Kaplan-Meier plots of the overall and event-free survivals for the entire cohort are shown in Supplementary Fig. 3 online. See Supplementary Note online for details. Using laboratory parameters at diagnosis for baseline levels, the following maximal responses were obtained: 12 participants (22\%) had a complete response, 38 participants $(72 \%)$ had a partial response and 3 participants $(6 \%)$ had a minimal response in accordance with standard criteria. At last update, 41 participants remained alive at a median follow-up time point of 16 months, and 23 participants were surviving event-free at a median follow-up time point of 13 months.

\section{DISCUSSION}

High-dose therapy followed by autologous stem cell transplantation is an effective means to achieve a minimal disease state and improve survival for myeloma. But relapses are frequent and cures are rare because of the lack of an effective antitumor immune response to eradicate minimal residual disease. In principle, the early posttransplant state is an ideal setting for immunotherapy given the reduction of tumor burden. But immunotherapy in the early posttransplant period has been unsuccessful to date, as the immune system is typically characterized by low lymphocyte counts and impaired immune-cell function during this time ${ }^{2}$. Animal models suggest that the early post-transplant period may be most appropriate for the induction of effective antitumor immune responses ${ }^{24,25}$, and furthermore that the combination of vaccine and adoptive immunotherapy may augment antitumor responses ${ }^{26}$. These animal models, along with prior clinical studies that showed poor post-transplant immune responses to antimicrobial vaccines ${ }^{13,27}$, suggested that combination immunotherapy to accelerate immune reconstitution might result in more rapid and potent induction of immunity. In the absence of an established myeloma vaccine, we first evaluated our strategy for reconstitution of immunity in the context of a randomized controlled study by testing a licensed pneumococcal vaccine.

Constriction of the T-cell repertoire and a variety of functional impairments ${ }^{2,22}$ contribute to the immunodeficiency that can persist 4-10 years after autologous stem cell transplantation ${ }^{28}$. We found that a single infusion of costimulated autologous $\mathrm{T}$ cells in the early posttransplant period accelerated the numerical and functional recovery of T cells. Robust numerical T-cell recovery has been previously observed in smaller nonrandomized studies of costimulated autologous T-cell infusions ${ }^{9,10}$, but this is the first randomized study to show accelerated $\mathrm{T}$ cell reconstitution, and the first demonstration of improved immune function. A corollary of our findings is that the large numbers of passenger $\mathrm{T}$ lymphocytes in the autologous peripheral blood stem cell product (range, $0.29-10.6 \times 10^{9}$ in this protocol) are not sufficient for rapid immune reconstitution and do not provide help for vaccination in the early post-transplant period. In addition, our results confirm previous studies showing a profound reduction of vaccine responses in recipients of autologous peripheral blood stem cell and bone marrow transplants within the first 2 years after transplant ${ }^{12,13}$.

Costimulated autologous T-cell infusions have been well tolerated in previous nonrandomized studies ${ }^{9,10}$. The early T-cell infusion subjects had a delayed $23 \%$ incidence of rash at a median of $13 \mathrm{~d}$ (range, 3-48) after T-cell infusion that was not observed in the early post-transplant period in Groups 2 and 4. The etiology of the rash 
remains to be determined, but the timing and appearance was typical of previous reports of autologous graft-versus-host disease ${ }^{1,29}$. It is not clear from our study whether T-cell costimulation is necessary for the augmentation of cellular and humoral immunity that was observed in Group 1. For practical matters, it was necessary to have an efficient culture system in order to achieve the target dose of $10^{10}$ adoptively transferred $\mathrm{T}$ cells. But it is possible that the increased T-cell numbers rather than their activated or costimulated state were primarily responsible for the enhanced immune responses.

Preclinical studies suggested that adoptive transfer would increase vaccine responses in individuals who had undergone transplants ${ }^{30}$, and mathematical modeling suggests that adoptive cell transfers could improve tumor immunotherapy ${ }^{31}$. This is among the first studies to show that adoptive transfer of antigen-primed, ex vivo costimulated $\mathrm{T}$ cells leads to accelerated immune reconstitution and enhanced antigen-specific $\mathrm{CD}^{+}$and $\mathrm{CD} 8^{+} \mathrm{T}$-cell function in vivo. This conclusion is based on two lines of evidence: first, antipneumococcal antibody responses to the T cell-dependent PCV were equivalent in Groups 1 and 2 after the pre-transplant immunization; however, only the response in Group 1 subjects was sustained and boosted by subsequent immunizations after transplant. The transient response in Group 2 subjects probably represents insufficient $\mathrm{CD} 4^{+} \mathrm{T}$ helper cell effects to sustain the B-cell expansion and differentiation, and is consistent with recent studies showing that age-related reductions in the cognate helper function of $\mathrm{CD}^{+}{ }^{+} \mathrm{T}$ cells contribute substantially to defects in B-cell function and impaired humoral responses observed in aged individuals $^{32}$. Second, the proliferative T-cell responses to the CRM197 carrier protein of the PCV were significantly greater in Group 1 subjects $(P<0.01)$. In contrast, $\mathrm{CD}^{+} \mathrm{T}$ cells in subjects from Groups 2-4 were anergic throughout the entire post-transplant period.

Our results agree with those from previous studies of PCV immunizations in individuals who have undergone autologous or allogeneic transplants ${ }^{33,34}$, which show that pre-transplant immunization results in higher pneumococcal antibody responses during the post-transplant period. T-cell responses were not examined in these studies.

An unexpected result from our study was that the proliferative response of $\mathrm{CMV}$-specific $\mathrm{CD}^{+}$and $\mathrm{CD}^{+} \mathrm{T}$ cells was enhanced in recipients of early $\mathrm{T}$-cell infusions. Further studies will be required to determine the mechanism of this effect, but it probably reflects contributions of accelerated numerical T-cell reconstitution as well as enhanced function of the T cells after early adoptive T-cell transfer. It is possible that relative depletion of regulatory $\mathrm{T}$ cells during the ex vivo expansion of the $\mathrm{T}$ cells to be infused also contributes to the robust immunity that we have observed. Lymphopenia in the early post-transplant period has been shown to promote homeostatic T-cell proliferation, a state in which naive and memory $\mathrm{T}$ cells compete with each other for expansion at the ultimate expense of naive $\mathrm{T}$ cells. This process can lead to enhanced function of $\mathrm{T}$ cells in animal models ${ }^{35}$. Given that none of our subjects experienced activation of CMV infection, it is reasonable to assume that the increased function and or numbers of CMV-specific T cells was antigen independent, and perhaps related to $\mathrm{CD} 4^{+} \mathrm{T}$ helper cells that can prevent the development of 'helpless' $\mathrm{CD}^{+} \mathrm{T}$ cells, memory $\mathrm{T}$ cells that are unable to proliferate upon antigenic stimulation ${ }^{36}$. Our observation that early $\mathrm{T}$-cell infusions prevented impaired $\mathrm{CD}^{+} \mathrm{T}$-cell proliferation in response to SEB in the early post-transplant period is consistent with this hypothesis, although other interpretations are possible. Previous studies have documented profound $\mathrm{CD} 4^{+} \mathrm{T}$-cell dysfunction after autologous stem cell transplantation ${ }^{2,37}$.

Our protocol consisting of pre-transplant immunization followed by a single early post-transplant infusion of costimulated $\mathrm{T}$ cells resulted in rapid immunologic reconstitution, as assessed by potentially protective levels of pneumococcal antibody within $30 \mathrm{~d}$ after transplant, and normal or above-normal antigen-specific T-cell proliferation in the early post-transplant period. We believe that the magnitude of immune reconstitution was clinically meaningful, as protective levels of antibody are estimated to be about $0.5 \mu \mathrm{g} / \mathrm{ml}^{15,16}$. In addition, the observation that many subjects in Group 1 had antibody levels that were equivalent to or higher than those reported in previous PCV studies of normal older adults ${ }^{17-19}$, adults in general $^{20,21}$ and children ${ }^{11,38-41}$ indicates the robustness of the antibody responses obtained in this cohort of immunosuppressed subjects. There was substantial intersubject variability in the magnitude of the antibody responses observed, and this could reflect a number of factors, including previous clinical or subclinical pneumococcal infections, the type and cumulative amounts of previous cytotoxic chemotherapy, and the immunosuppressive effects from previous corticosteroid therapy.

The mechanism for the robust immunity in Group 1 subjects remains to be determined. It will be crucial to determine the relative contributions of antigen-dependent expansion of PCV-specific memory $\mathrm{T}$ cells during the ex vivo polyclonal stimulation or to the antigen dependent homeostatic expansion that may occur in vivo in the lymphopenic recipient. Alternatively, indirect mechanisms such as cytokine release from the infused expanded polyclonal population contributing to homeostatic expansion in vivo could be relevant.

Our long-term goal is to rebuild immunity early after cytotoxic therapy, decreasing infections and preventing relapse. It is hoped that this study may provide a platform for the design of future studies using $\mathrm{T}$ cells and tumor vaccines to eradicate minimal residual disease after transplant. The combination of active and passive immunotherapy evaluated in this study is a safe and potentially effective method for inducing post-transplant immune responses. Further studies are required to determine whether the principles observed here can be applied to tumor immunity.

\section{METHODS}

For details, see Supplementary Methods online.

Subjects and treatment. Study participants were at least 18 years old, with newly diagnosed myeloma that required systemic treatment. Most of the participants had already received induction therapy for myeloma by their referring oncologist. Untreated participants received one or two courses of pulse dexamethasone ${ }^{42}$. All participants gave written informed consent upon enrollment, which was performed in accordance with the Declaration of Helsinki; we obtained approval for the study from the institutional review boards of the University of Pennsylvania and the University of Maryland and from the US Food and Drug Administration.

From February 2002 to January 2004, we enrolled 54 participants at two centers ( 12 in the run-in phase, and 42 in the randomized phase). Eighteen of the 20 participants in Groups 1 and 2 received the three intended PCV immunizations; one participant in Group 1 did not receive the third (day 90) immunization because of a strong local reaction to the day 30 posttransplant immunization, and one participant in Group 2 did not receive the third (day 90) immunization because of mortality at day +85 after transplant. All 22 participants who were assigned to Groups 3 and 4 received the two intended post-transplant PCV immunizations at days 30 and 90. The median age was 56 years, $67 \%$ were male, and $19 \%$ were black. IgG and IgA paraproteins were present in $58 \%$ and $22 \%$ of participants respectively, whereas $20 \%$ had light-chain excretion only. There were no significant differences between the groups with respect to participant age, marrow plasmacytosis, diagnostic $\beta 2$ microglobulin levels, gender, number of prior treatments, proportion with abnormal cytogenetic studies and paraprotein subtypes. We thawed and cultured autologous T cells as specified in an US Food and Drug Administration-approved investigational new drug application ${ }^{9,43}$. 
Safety and toxicity. The costimulated T-cell infusions were well-tolerated. For T-cell infusion-related events, see Table 3.

Study design and treatment. We carried out a single nonrandomized arm runin phase to show the safety and feasibility of T-cell collection and expansion in this subject population and to finalize logistical details. Twelve subjects participated in this phase. We enrolled 42 participants in a second phase of the protocol in which ex vivo costimulated T-cell infusions were combined with PCV (Prevnar) immunizations.

Laboratory end points. Primary end points for the study were numeric and functional B and T-lymphocyte recovery. We assessed antibody responses to four of the seven vaccine serotypes $(6 \mathrm{~B}, 14,19 \mathrm{~F}, 23 \mathrm{~F})$ by ELISA binding assays ${ }^{44}$. We evaluated numeric T-cell recovery by enumeration of $\mathrm{CD}^{+}$and $\mathrm{CD} 8^{+}$ lymphocytes at days 30, 42, 90 and 180 after transplant, with day 42 chosen as the primary endpoint to evaluate the efficacy of T-cell infusions, as Groups 1 and 3 had been infused at this point, whereas Groups 2 and 4 had not. We assessed T-cell responses to the CRM-197 carrier protein of the PCV by CFSE staining on day 6 of culture of peripheral blood mononuclear cells as described ${ }^{45}$. We used flow cytometry to gate first by forward and side scatter, then on viable cells (ViaProbe negative, BD Biosciences) to identify $\mathrm{CD} 4^{+}$or $\mathrm{CD}^{+} \mathrm{T}$ cells, and finally on the $\mathrm{CD} 25^{+} \mathrm{CFSE}^{\mathrm{dim}}$ quadrant to quantify the antigen-specific proliferative responses for each treatment group because previous studies have shown that all activated human $\mathrm{T}$ cells are $\mathrm{CD} 25^{+}$at this point in culture ${ }^{46}$. Because responses to conjugate vaccines reflect $\mathrm{T}$-cell help, we also evaluated functional T-cell reconstitution by measurement of IgG antibody responses to the PCV vaccine as described above.

Clinical end points. Secondary end points included myeloma responses and the projected overall and event-free survival rates. We evaluated the maximal myeloma responses as specified ${ }^{47}$.

Statistical analysis. We performed time-to-event analyses according to the Kaplan-Meier method. We used the Kruskal test or chi-squared test for comparisons of participants' characteristics in the randomized groups. We carried out pairwise comparisons of the ELISA-binding antibody levels at each timepoint using the Mann-Whitney nonparametric test or Student $t$-test after logarithmic transformation of the data. We examined the reproducibility of the ELISA by determination of the interassay percent coefficient of variation. The percent coefficient of variation differed by pneumococcal serotype and ranged (2) from $13.3 \%$ to $22.6 \%$ for the various serotypes, with a mean of $18.6 \%$ for all serotypes. For samples below threshold, ELISA values were assigned a value of $50 \%$ of the lower limit of detection. We compared results from T-cell responses of CFSE dye-dilution experiments using two-sided $t$-test after logarithmic transformation of the data.

Note: Supplementary information is available on the Nature Medicine website.

\section{ACKNOWLEDGMENTS}

We thank R. Vonderheide, R. Carroll and J Riley for advice and intellectual assistance; M. Pohl and T. Yates for assistance with clinical data management, K. Grandfield, L. Winestone, M. Shalwala and A. Cannon for technical assistance, and H. Standiford, J. Karp, L. Schuchter, D. Molrine and H. Hamilton for serving on the Data Safety and Monitoring Committee, C. Hass for administrative assistance. We received support from a Specialized Center of Research and Clinical Scholars Award supported by the Leukemia and Lymphoma Society of America, National Institute of Allergy and Infectious Diseases contract no. N01-AI-85342 US National Cancer Institute grant R21 CA101356-2 and a Fellows' Grant from the Multiple Myeloma Research Foundation.

\section{COMPETING INTERESTS STATEMENT}

The authors declare competing financial interests (see the Nature Medicine website for details).

Published online at http://www.nature.com/naturemedicine/

Reprints and permissions information is available online at http://npg.nature.com/ reprintsandpermissions/

1. Anderson, K.C. et al. T-cell-depleted autologous bone marrow transplantation therapy: analysis of immune deficiency and late complications. Blood 76, 235-244 (1990).
2. Guillaume, T., Rubinstein, D.B. \& Symann, M. Immune reconstitution and immunotherapy after autologous hematopoietic stem cell transplantation. Blood 92, 14711490 (1998).

3. Porrata, L.F. et al. Early lymphocyte recovery predicts superior survival after autologous hematopoietic stem cell transplantation in multiple myeloma or non-Hodgkin lymphoma. Blood 98, 579-585 (2001).

4. Dhodapkar, M.V., Krasovsky, J. \& Olson, K. T cells from the tumor microenvironment of patients with progressive myeloma can generate strong, tumor-specific cytolytic responses to autologous, tumor-loaded dendritic cells. Proc. Natl Acad. Sci. USA 99, 13009-13013 (2002)

5. Noonan, K. et al. Activated marrow-infiltrating lymphocytes effectively target plasma cells and their clonogenic precursors. Cancer Res. 65, 2026-2034 (2005).

6. Li, L., Yee, C. \& Beavo, J.A. CD3- and CD28-dependent induction of PDE7 required for T cell activation. Science 283, 848-851 (1999).

7. Boussiotis, V.A. et al. p27kip1 functions as an anergy factor inhibiting interleukin 2 transcription and clonal expansion of alloreactive human and mouse helper T lymphocytes. Nat. Med. 6, 290-297 (2000).

8. Levine, B.L. et al. Adoptive Transfer of Costimulated CD4+ T cells Induces Expansion of Peripheral T Cells and Decreased CCR5 Expression in HIV Infection. Nat. Med. 8 47-53 (2002)

9. Laport, G.G. et al. Adoptive transfer of costimulated T cells induces lymphocytosis in patients with relapsed/refractory non-Hodgkin lymphoma following CD34+-selected hematopoietic cell transplantation. Blood 102, 2004-2013 (2003).

10. Rapoport, A.P. et al. Molecular remission of CML after autotransplantation followed by adoptive transfer of costimulated autologous T cells. Bone Marrow Transplant. 33, 5360 (2004).

11. Black, S. et al. Efficacy, safety and immunogenicity of heptavalent pneumococca conjugate vaccine in children. Northern California Kaiser Permanente Vaccine Study Center Group. Pediatr. Infect. Dis. J. 19, 187-195 (2000).

12. Gandhi, M.K. et al. Antibody responses to vaccinations given within the first two years after transplant are similar between autologous peripheral blood stem cell and bone marrow transplant recipients. Bone Marrow Transplant. 28, 775-781 (2001).

13. Guinan, E.C. et al. Polysaccharide conjugate vaccine responses in bone marrow transplant patients. Transplantation 57, 677-684 (1994).

14. Romero-Steiner, S. et al. Reduction in functional antibody activity against Streptococcus pneumoniae in vaccinated elderly individuals highly correlates with decreased IgG antibody avidity. Clin. Infect. Dis. 29, 281-288 (1999).

15. Jokinen, J.T., Ahman, H., Kilpi, T.M., Makela, P.H. \& Kayhty, M.H. Concentration of antipneumococcal antibodies as a serological correlate of protection: an application to acute otitis media. J. Infect. Dis. 190, 545-550 (2004).

16. Jodar, L. et al. Serological criteria for evaluation and licensure of new pneumococcal conjugate vaccine formulations for use in infants. Vaccine $21,3265-3272$ (2003).

17. Powers, D.C., Anderson, E.L., Lottenbach, K. \& Mink, C.M. Reactogenicity and immunogenicity of a protein-conjugated pneumococcal oligosaccharide vaccine in older adults. J. Infect. Dis. 173, 1014-1018 (1996).

18. Shelly, M.A. et al. Comparison of pneumococcal polysaccharide and CRM197conjugated pneumococcal oligosaccharide vaccines in young and elderly adults. Infect. Immun. 65, 242-247 (1997).

19. Lottenbach, K.R. et al. Age-associated differences in immunoglobulin G1 (IgG1) and IgG2 subclass antibodies to pneumococcal polysaccharides following vaccination. Infect. Immun. 67, 4935-4938 (1999).

20. Shelly, M.A., Pichichero, M.E. \& Treanor, J.J. Low baseline antibody level to diphtheria is associated with poor response to conjugated pneumococcal vaccine in adults. Scand. J. Infect. Dis. 33, 542-544 (2001).

21. Kamboj, K.K., Kirchner, H.L., Kimmel, R., Greenspan, N.S. \& Schreiber, J.R. Significant variation in serotype-specific immunogenicity of the seven-valent Streptococcus pneumoniae capsular polysaccharide-CRM197 conjugate vaccine occurs despite vigorous $\mathrm{T}$ cell help induced by the carrier protein. J. Infect. Dis. 187, 1629-1638 (2003).

22. Hakim, F.T. et al. Age-dependent incidence, time course, and consequences of thymic renewal in adults. J. Clin. Invest. 115, 930-939 (2005).

23. Uchida, T., Pappenheimer, A.M. Jr \& Greany, R. Diphtheria toxin and related proteins. I. Isolation and properties of mutant proteins serologically related to diphtheria toxin. J. Biol. Chem. 248, 3838-3844 (1973).

24. Borrello, I. et al. Sustaining the graft-versus-tumor effect through posttransplant immunization with granulocyte-macrophage colony-stimulating factor (GM-CSF)-producing tumor vaccines. Blood 95, 3011-3019 (2000).

25. Teshima, T. et al. Tumor cell vaccine elicits potent antitumor immunity after allogeneic T-cell-depleted bone marrow transplantation. Cancer Res. 61, 162-171 (2001).

26. Overwijk, W.W. et al. Tumor regression and autoimmunity after reversal of a functionally tolerant state of self-reactive CD8+ T cells. J. Exp. Med. 198, 569-580 (2003).

27. Singhal, S. \& Mehta, J. Reimmunization after blood or marrow stem cell transplantation. Bone Marrow Transplant. 23, 637-646 (1999).

28. Nordoy, T. et al. Humoral immunity to viral and bacterial antigens in lymphoma patients 4-10 years after high-dose therapy with ABMT. Serological responses to revaccinations according to EBMT guidelines. Bone Marrow Transplant. 28, 681-687 (2001).

29. Jones, R.J. et al. Induction of graft-versus-host disease after autologous bone marrow transplantation. Lancet 1, 754-757 (1989). 
30. Vavassori, M. et al. Restricted TCR repertoire and long-term persistence of donorderived antigen-experienced CD4+ T cells in allogeneic bone marrow transplantation recipients. J. Immunol. 157, 5739-5747 (1996).

31. Kirschner, D. \& Panetta, J.C. Modeling immunotherapy of the tumor-immune interaction. J. Math. Biol. 37, 235-252 (1998).

32. Eaton, S.M., Burns, E.M., Kusser, K., Randall, T.D. \& Haynes, L. Age-related defects in CD4 T cell cognate helper function lead to reductions in humoral responses. J. Exp. Med. 200, 1613-1622 (2004).

33. Molrine, D.C. et al. Donor immunization with pneumococcal conjugate vaccine and early protective antibody responses following allogeneic hematopoietic cell transplantation. Blood 101, 831-836 (2003).

34. Antin, J.H. et al. Protective antibody responses to pneumococcal conjugate vaccine after autologous hematopoietic stem cell transplantation. Biol. Blood Marrow Transplant. 11, 213-222 (2005)

35. Dummer, W. et al. T cell homeostatic proliferation elicits effective antitumor autoimmunity. J. Clin. Invest. 110, 185-192 (2002).

36. Janssen, E.M. et al. CD4+ T-cell help controls CD8+ T-cell memory via TRAILmediated activation-induced cell death. Nature 434, 88-93 (2005)

37. Heitger, A. et al. Defective T-helper cell function after T-cell-depleting therapy affecting naive and memory populations. Blood 99, 4053-4062 (2002).

38. Shinefield, H.R. et al. Safety and immunogenicity of heptavalent pneumococcal CRM197 conjugate vaccine in infants and toddlers. Pediatr. Infect. Dis. J. 18, 757-763 (1999)

39. Eskola, J. et al. Efficacy of a pneumococcal conjugate vaccine against acute otitis media. N. Engl. J. Med. 344, 403-409 (2001).
40. de Aristegui, F.J. et al. Evaluation of the safety and immunogenicity of pneumococcal seven-valent conjugate vaccine (Prevenar) administered in previously unvaccinated Spanish children aged 24 to 36 months. Vaccine 23, 1917-1922 (2005).

41. Ekstrom, N. et al. Kinetics and avidity of antibodies evoked by heptavalent pneumococcal conjugate vaccines PncCRM and PncOMPC in the Finnish Otitis Media Vaccine Trial. Infect. Immun. 73, 369-377 (2005).

42. Alexanian, R., Dimopoulos, M.A., Delasalle, K. \& Barlogie, B. Primary dexamethasone treatment of multiple myeloma. Blood 80, 887-890 (1992).

43. Levine, B.L. et al. Effects of CD28 costimulation on long term proliferation of CD4+ $T$ cells in the absence of exogenous feeder Cells. J. Immunol. 159, 5921-5930 (1997).

44. Concepcion, N.F \& Frasch, C.E. Pneumococcal type $22 f$ polysaccharide absorption improves the specificity of a pneumococcal-polysaccharide enzyme-linked immunosorbent assay. Clin. Diagn. Lab. Immunol. 8, 266-272 (2001).

45. Wells, A.D., Gudmundsdottir, H. \& Turka, L.A. Following the fate of individual T cells throughout activation and clonal expansion. Signals from T cell receptor and CD28 differentially regulate the induction and duration of a proliferative response. J. Clin. Invest. 100, 3173-3183 (1997).

46. Novak, E.J., Liu, A.W., Nepom, G.T. \& Kwok, W.W. MHC class II tetramers identify peptide-specific human $\mathrm{CD} 4(+) \mathrm{T}$ cells proliferating in response to influenza $\mathrm{A}$ antigen. J. Clin. Invest. 104, R63-R67 (1999).

47. Blade, J. et al. Criteria for evaluating disease response and progression in patients with multiple myeloma treated by high-dose therapy and haemopoietic stem cell transplantation. Myeloma Subcommittee of the EBMT. European Group for Blood and Marrow Transplant. Br. J. Haematol. 102, 1115-1123 (1998). 